Provided for non-commercial research and education use. Not for reproduction, distribution or commercial use.

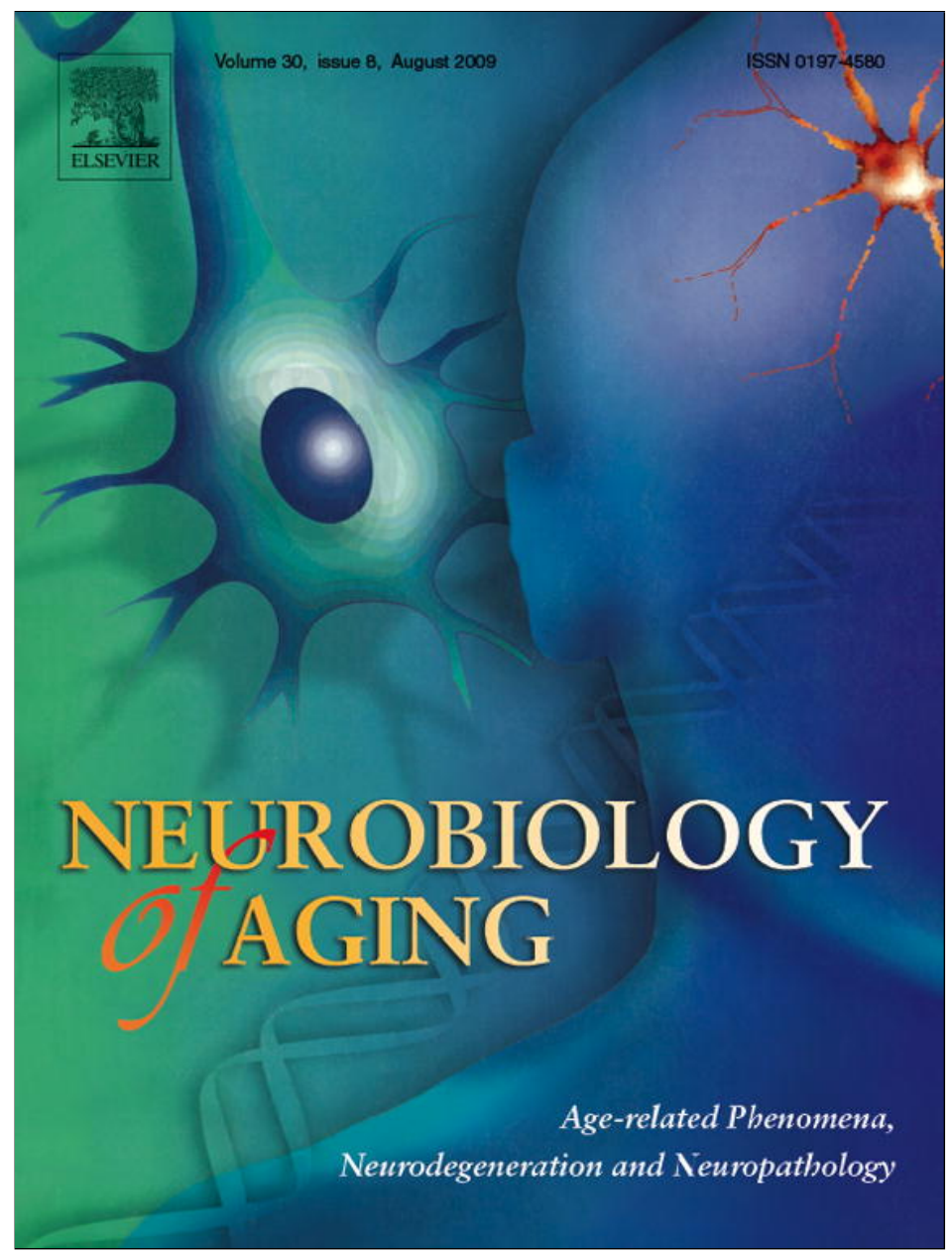

This article appeared in a journal published by Elsevier. The attached copy is furnished to the author for internal non-commercial research and education use, including for instruction at the authors institution and sharing with colleagues.

Other uses, including reproduction and distribution, or selling or licensing copies, or posting to personal, institutional or third party websites are prohibited.

In most cases authors are permitted to post their version of the article (e.g. in Word or Tex form) to their personal website or institutional repository. Authors requiring further information regarding Elsevier's archiving and manuscript policies are encouraged to visit:

http://www.elsevier.com/copyright 


\title{
Two Italian kindreds with familial amyotrophic lateral sclerosis due to FUS mutation
}

\author{
Adriano Chiò $^{\mathrm{a}, *, 1}$, Gabriella Restagno ${ }^{\mathrm{b}, 1}$, Maura Brunetti ${ }^{\mathrm{b}}$, Irene Ossola ${ }^{\mathrm{b}}$, Andrea Calvo ${ }^{\mathrm{a}}$, \\ Gabriele Mora $^{\mathrm{c}}$, Mario Sabatelli ${ }^{\mathrm{d}}$, Maria Rosaria Monsurrò ${ }^{\mathrm{e}}$, Stefania Battistini ${ }^{\mathrm{f}}$, \\ Jessica Mandrioli g, Fabrizio Salvi h, Rossella Spataro ${ }^{i}$, Jennifer Schymick ${ }^{j}$, \\ Bryan J. Traynor ${ }^{j}$, Vincenzo La Bella ${ }^{\mathrm{i}}$, the ITALSGEN Consortium ${ }^{2}$ \\ ${ }^{a}$ ALS Center, Department of Neuroscience, University of Turin, Via Cherasco 15, 10126 Turin, Italy \\ ${ }^{\mathrm{b}}$ Molecular Genetics Unit, Department of Clinical Pathology, ASO, O.I.R.M.-S.Anna, Turin, Italy \\ ${ }^{\mathrm{c}}$ ALS Center, Salvatore Maugeri Foundation, Milano, Italy \\ ${ }^{\mathrm{d}}$ Neurological Institute, Catholic University and I.CO.M.M. Association for ALS Research, Rome, Italy \\ ${ }^{\mathrm{e}}$ Department of Neurological Sciences, Second University of Naples, Italy \\ ${ }^{\mathrm{f}}$ Department of Neuroscience, Neurology Section, University of Siena, Siena, Italy \\ g Department of Neuroscience, S. Agostino-Estense Hospital, and University of Modena, Italy \\ ${ }^{\mathrm{h}}$ Center for Diagnosis and Cure of Rare Diseases, Department of Neurology, Bellaria Hospital, Bologna, Italy \\ ${ }^{\mathrm{i}}$ Department of Clinical Neurosciences, University of Palermo, Italy \\ j Laboratory of Neurogenetics, National Institute on Aging, NIH, Bethesda, MD, USA
}

Received 29 April 2009; accepted 1 May 2009

Available online 17 May 2009

\begin{abstract}
Recently, fused in sarcoma/translated in liposarcoma (FUS/TLS) gene, located on chromosome 16p11.2, has been identified as a disease gene in familial amyotrophic lateral sclerosis (FALS). We have analyzed FUS/TLS in a cohort of 52 index cases from seven Italian regions with non-SOD1 and non-TARDBP FALS. We identified a heterozygous c.G1542C missense mutation in a family of northern Italian origin, and a heterozygous c.C1574T missense mutation in a family of Sicilian origin. Both variants are located in exon 15 encoding the RNA-recognition motif, and result in a substitution of an arginine with a serine in position 514 (p.R514S) and substitution of a proline with a leucine at position 525 (p.P525L), respectively. Overall, the two mutations accounted for 3.8\% of 52 non-SOD1 and non-TDP43 index cases of FALS. The clinical phenotype was similar within each of the families, with a predominantly upper limb onset in the family carrying the p.R514S mutation and bulbar onset, with very young age and a rapid course in the family carrying the p.P525L mutation.
\end{abstract}

(C) 2009 Elsevier Inc. All rights reserved.

Keywords: Amyotrophic lateral sclerosis; Genetics; FUS gene; Family pedigrees

\section{Introduction}

Amyotrophic lateral sclerosis (ALS) is a fatal neurodegenerative disorder of cortical, bulbar and spinal motor neurons, clinically characterized by progressive paralysis and ultimately death due to respiratory failure typically within 3 years

\footnotetext{
* Corresponding author. Tel.: +39 0116335439; fax: +39 0116963487.

E-mail address: achio@usa.net (A. Chiò).

1 These authors contributed equally to this work.

2 See Appendix A for the other members of ITALSGEN.
}

of symptom onset. Approximately $5 \%$ of cases are familial in nature (FALS), whereas the majority of cases occur sporadically in the community (SALS) (Chiò et al., 2008). Among FALS, 15-20\% are caused by mutations in the superoxide dismutase (SOD1) gene (Rosen et al., 1993), and a further $5-10 \%$ are due to pathogenic mutations in the TAR DNA binding protein (TARDBP) gene (Sreedharan et al., 2008).

Recently, fused in sarcoma/translated in liposarcoma (FUS/TLS) gene has been identified as a disease gene in FALS (Kwiatkowski et al., 2009; Vance et al., 2009). Located on chromosome 16p11.2, this gene encodes for a 526-amino 
acid protein that binds RNA and is known to be involved in RNA processing. Almost all ALS-linked mutations identified to date are clustered in the RNA-recognition motif domain located at the $\mathrm{C}$ terminus of the protein.

In this study, we present genetic analysis data on FUS/TLS in a cohort of 52 index cases from seven Italian regions with non-SOD1 and non-TARDBP FALS to further define the spectrum and frequency of FUS/TLS mutations.

\section{Methods}

\subsection{Subjects}

DNA sample from 52 index cases with FALS were collected from eight Italian ALS referral centres (Torino, Pavia, Modena, Bologna, Siena, Roma, Napoli, and Palermo). All cases were diagnosed as having definite, probable or probable laboratory-supported ALS according to revised El Escorial criteria (Brooks et al., 2000). Mutations in SOD1 and TARDBP genes were excluded before the inclusion in the present study. Control samples were obtained from 280 healthy individuals matched to cases by age, gender, and Italian region of origin. Written informed consent for genetic analysis was obtained from each individual.

\subsection{Genetic analysis}

Genomic DNA was extracted from peripheral blood with the Biorobot MDX DSP Qiagen. Exons 1-14 of FUS gene were sequenced as previously described (Vance et al., 2009). Exon 15 of FUS was PCR amplified with the following primers: forward sequence TCGCTGGGTTAGGTAGGAGG, reverse sequence TATTCCAGTTCCTGCTGGGC. PCR products were sequenced using the Big-Dye Termina- tor v3.1 sequencing kit (Applied Biosystem) and run on an ABIPrism 3100Avant genetic analyzer. Exon 15 was also sequenced in 280 control individuals.

\section{Results}

We performed mutational screening of the FUS gene in 52 index patients from Italian kindreds with familial ALS. We identified a heterozygous c.G1542C missense mutation in a family of northern Italian (Piedmont) origin (Family A), and a heterozygous c.C1574T missense mutation in a second family of Sicilian origin (Family B). Both variants are located in exon 15 encoding the RNA-recognition motif, and result in a substitution of an arginine with a serine in position 514 (p.R514S) and substitution of a proline with a leucine at position 525 (p.P525L), respectively. DNA was not available from other members of either family, so it was not possible to confirm segregation. However, the mutations were not found in 280 control samples. Apart from a synonymous mutation in exon 15 of another FALS index case (c.G1566A), no other exonic variant was detected.

\subsection{Family A (Piedmont, northern Italy)}

The index case IV-1 (Fig. 1, Supplementary Table 1) developed lower limb weakness at 36 years of age. His symptoms progressed rapidly to involve neck and respiratory muscles with generalized hyperreflexia. EMG at the time of presentation confirmed acute and chronic alterations in all limbs and the thoracic muscles. CSF examination and MRI of the brain and the spinal cord were normal. The patient died of respiratory failure 22 months after symptom onset.

His father (III-1), an obligate gene carrier, died at 69 years of age from lung cancer without signs of ALS or

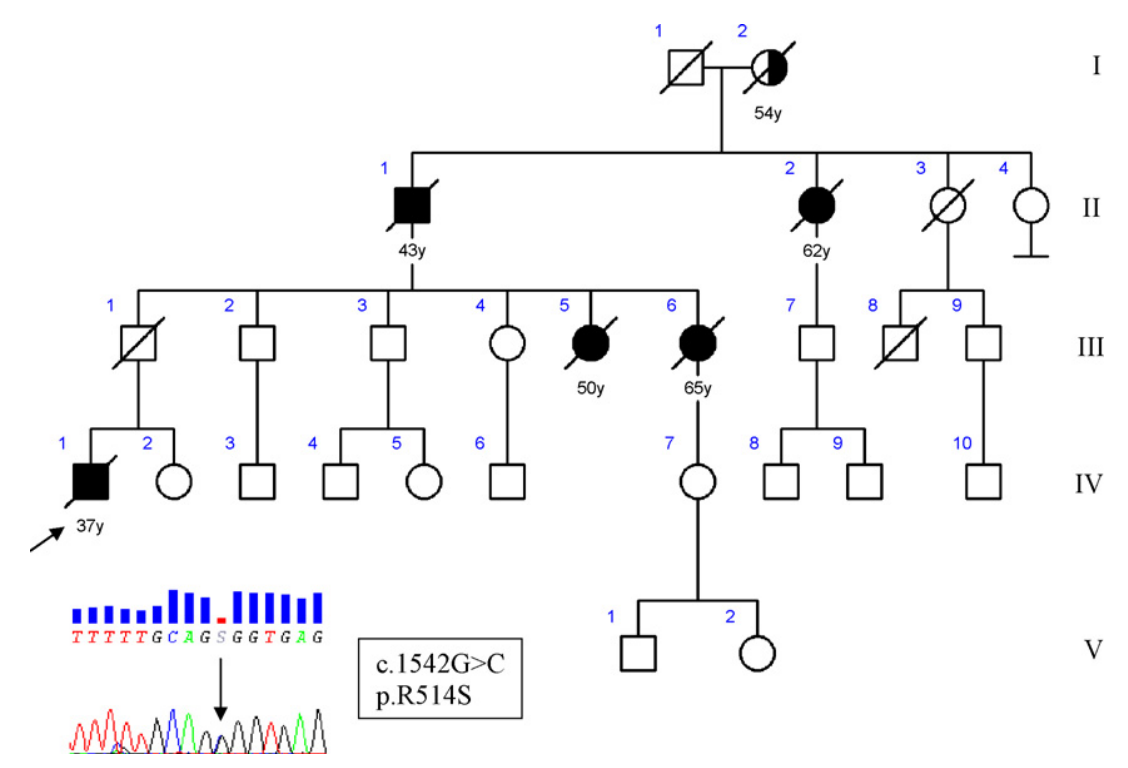

Fig. 1. Pedigree of family A with chromatogram of part of exon 15 of FUS showing single base change c. $1542 \mathrm{G}>\mathrm{C}$ in the index patient, substituting arginine for serine in position 514. Square indicates male; circle, female; slash, deceased; solid symbol, affected; and arrow, index patient. 


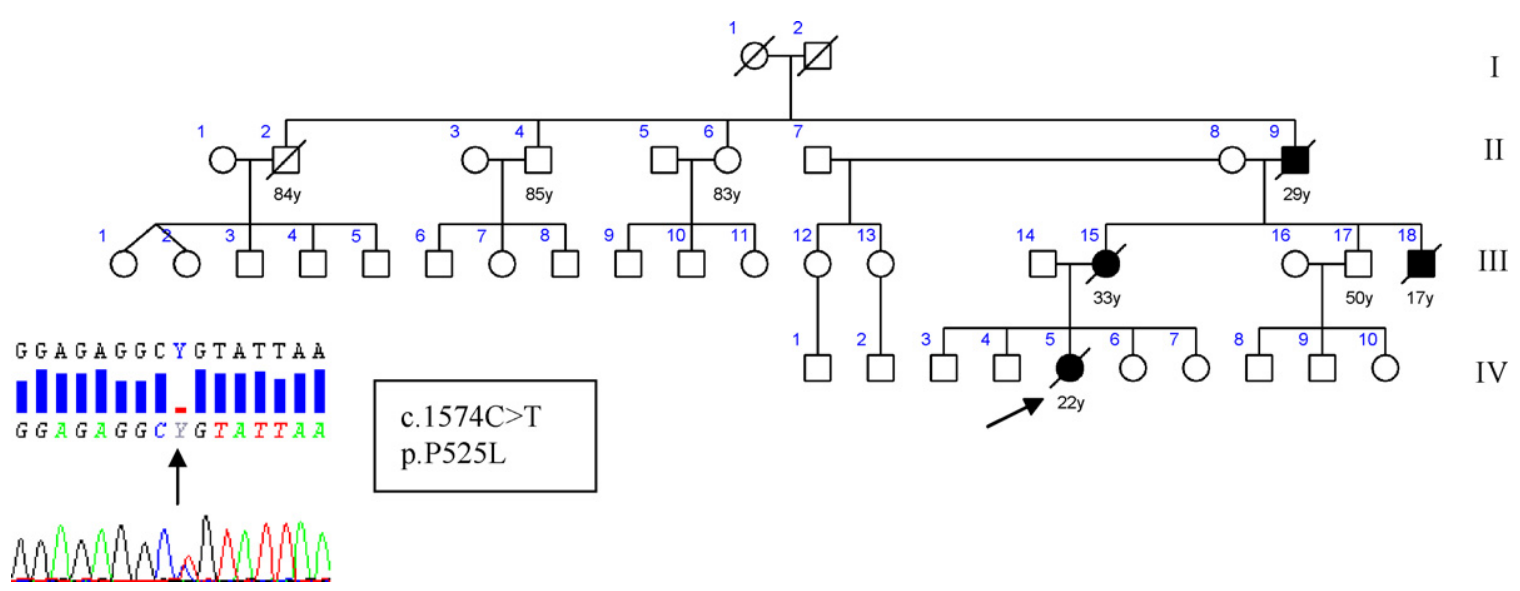

Fig. 2. Pedigree of family B. Pedigree of family B with chromatogram of part of exon 15 of FUS showing single base change c.1574C $>$ T in the index patient, substituting proline for leucine in position 525. Square indicates male; circle, female; slash, deceased; solid symbol, affected; and arrow, index patient.

neuromuscular disorders. Two paternal sisters of the index case developed hands and shoulder girdle weakness at age 48 (III-5) and 64 (III-6), respectively. Symptoms were rapidly progressive, were associated with generalized hyperreflexia, and they died from respiratory failure 25 and 15 months after onset. The paternal grandfather (II-1) of the index case developed asymmetrical shoulder girdle weakness at age 41 , and died from respiratory failure 22 months later. His sister (II-2) developed right hand wasting at 60 years of age. Her symptoms spread rapidly to involve her bulbar musculature and she died from respiratory failure 19 months after symptom onset. The mother of II-1 and II-2 (I-1) presented with right shoulder atrophy at 52 and died from respiratory failure 2 years later. Autopsy material was not available from any of the deceased family members.

\subsection{Family B (Sicily, southern Italy)}

The index case IV-3 (Fig. 2, Supplementary Table 2) presented at 21 years of age with a 3-month history of rapidly progressive bulbar dysfunction. Her symptoms spread quickly to involve her upper limbs with generalized hyperreflexia. EMG at the time of presentation confirmed active and chronic denervation in upper limbs. CSF examination, biochemical profile, and MRI brain and spinal cord were normal. The patient died of respiratory failure less than 1 year after the onset of ALS.

Both her mother (III-13) and a maternal uncle (III-16) died at 33 and 17, from aggressive bulbar-onset motor neuron disease leading to respiratory failure in less than 1 year. Her maternal grandfather (II-7) developed rapidly progressive upper limb atrophy and weakness and respiratory failure and died less than 2 years later due to respiratory failure.

\section{Discussion}

In the present paper, we screened a cohort of 52 Italian patients diagnosed with FALS and identified two multi- generational families carrying mutations in the FUS gene. The two mutations accounted for $3.8 \%$ of 52 non-SOD1 and non-TDP43 index cases of FALS, a frequency similar to that found in series of 197 index cases of British and Australian FALS kindreds (4.1\%) (Vance et al., 2009). Although it was not possible to confirm segregation of the mutations with disease within the families, these variants are likely to be pathogenic, as they were not found in 280 normal Italian control subjects. Furthermore, although the c.G1542C variant has not been previously reported, a $\mathrm{G}$ to $\mathrm{T}$ transversion at the same base pair leading to the same p.R514S amino acid change has previously been identified in a FALS case (Kwiatkowski et al., 2009). Finally, the c.C1574T mutation was also previously identified in a familial case (Kwiatkowski et al., 2009).

The clinical phenotype was similar within each of the families. Family A was characterized by a relatively young mean age at onset (50 years; SD 11.1), predominantly upper limb onset, clear UMN involvement, and rapid progression to respiratory failure and death. Mean disease duration from onset was 21.2 months (SD 3.7). One obligate carrier (III-1) deceased at 69 without any sign of ALS, indicating a possible reduced penetrance.

In contrast to Family A, the clinical phenotype of Family $\mathrm{B}$ is dominated by bulbar dysfunction (presenting symptom in three out of four cases), a young age at onset (mean, 23.7; SD 7.1) and rapid progression (death in less than 12 months in three out of four of the cases). The clinical pattern observed in our family is similar to that already reported for this mutation (mean age of onset $=22$ years, mean disease duration $=6$ months) (Kwiatkowski et al., 2009) confirming that this particular FUS mutation results in a highly aggressive form of ALS.

In summary, the identification of two Italian kindreds of different origin with FALS due to FUS/TLS missense mutations indicates the widespread diffusion of this mutation. Together with the figures reported in other studies (Vance et al., 2009), it seems that the occurrence of FUS/TLS mutations is about $4 \%$ of non-SOD1 and non-TDP43 FALS. 


\section{Conflict of interest}

The authors have no conflicts of interests.

\section{Acknowledgements}

The work was supported by Ministero della Salute, Ricerca Sanitaria Finalizzata 2007 (to AC, GR and GM); Fondazione Vialli e Mauro for ALS, Torino (to AC and GM); and Regione Piemonte, Progetti Finalizzati (to GR). This research was supported in part by the Intramural Research Program of the NIH, National Institute on Aging (Z01-AG000949-02).

\section{Appendix A. Other members of the ITALSGEN Consortium}

Fabio Giannini (Siena), Claudia Ricci (Siena), Cristina Moglia (Turin), Federica Lombardo (Turin), Luca Sbaiz (Turin), Stefania Cammarosano (Turin), Gioacchino Tedeschi (Naples), Patrizia Sola (Modena), Ilaria Bartolomei (Bologna), Kalliopi Marinou (Milan), Laura Papetti (Milan), Amelia Conte (Rome), Marco Luigetti (Rome), Piera Paladino (Palermo), Claudia Caponnetto (Genua), Gabriele Siciliano (Pisa).

\section{Appendix B. Supplementary data}

Supplementary data associated with this article can be found, in the online version, at doi:10.1016/j.neurobiolaging. 2009.05.001.

\section{References}

Brooks, B.R., Miller, R.G., Swash, M., Munsat, T.L., World Federation of Neurology Research Group on Motor Neuron Diseases, 2000. El Escorial revisited: revised criteria for the diagnosis of amyotrophic lateral sclerosis. Amyotroph Lateral Scler Other Motor Neuron Disord 1, 293-299.

Chiò, A., Traynor, B.J., Lombardo, F., Fimognari, M., Calvo, A., Ghiglione, P., Mutani, R., Restagno, G., 2008. Prevalence of SOD1 mutations in the Italian ALS population. Neurology 70, 533-537.

Kwiatkowski Jr., T.J., Bosco, D.A., Leclerc, A.L., Tamrazian, E., Vanderburg, C.R., Russ, C., Davis, A., Gilchrist, J., Kasarskis, E.J., Munsat, T., Valdmanis, P., Rouleau, G.A., Hosler, B.A., Cortelli, P., de Jong, P.J., Yoshinaga, Y., Haines, J.L., Pericak-Vance, M.A., Yan, J., Ticozzi, N., Siddique, T., McKenna-Yasek, D., Sapp, P.C., Horvitz, H.R., Landers, J.E., Brown Jr., R.H., 2009. Mutations in the FUS/TLS gene on chromosome 16 cause familial amyotrophic lateral sclerosis. Science 323, 1205-1208.

Rosen, D.R., Siddique, T., Patterson, D., Figlewicz, D.A., Sapp, P., Hentati, A., Donaldson, D., Goto, J., O’Regan, J.P., Deng, H.X., Rahmani, Z., Krizus, A., McKenna-Yasek, D., Cayabyab, A., Gaston, S.M., Berger, R., Tanzi, R.E., Halperin, J.J., Herzfeldt, B., Van den Bergh, R., Hung, W.-Y., Bird, T., Deng, G., Mulder, D.W., Smyth, C., Laing, N.G., Soriano, E., Pericak-Vance, M.A., Haines, J., Rouleau, G.A., Gusella, J.S., Horvitz, H.R., Brown Jr., R.H., 1993. Mutations in Cu/Zn superoxide dismutase gene are associated with familial amyotrophic lateral sclerosis. Nature 362, 59-62.

Sreedharan, J., Blair, I.P., Tripathi, V.B., Hu, X., Vance, C., Rogelj, B., Ackerley, S., Durnall, J.C., Williams, K.L., Buratti, E., Baralle, F., de Belleroche, J., Mitchell, J.D., Leigh, P.N., Al-Chalabi, A., Miller, C.C., Nicholson, G., Shaw, C.E., 2008. TDP-43 mutations in familial and sporadic amyotrophic lateral sclerosis. Science 319, 1668-1672.

Vance, C., Rogelj, B., Hortobágyi, T., De Vos, K.J., Nishimura, A.L., Sreedharan, J., Hu, X., Smith, B., Ruddy, D., Wright, P., Ganesalingam, J., Williams, K.L., Tripathi, V., Al-Saraj, S., Al-Chalabi, A., Leigh, P.N., Blair, I.P., Nicholson, G., de Belleroche, J., Gallo, J.M., Miller, C.C., Shaw, C.E., 2009. Mutations in FUS, an RNA processing protein, cause familial amyotrophic lateral sclerosis type 6. Science 323 , 1208-1211. 